\title{
Parâmetros psicométricos das escalas de qualidade dos papéis desempenhados pela mulher: mãe e trabalho pago
}

\author{
Izabel Cristina Possatti \\ Mardonio Rique Dias \\ Universidade Federal da Paraíba
}

\begin{abstract}
Resumo
A necessidade de avaliar a qualidade de papéis desempenhados por mulheres no trabalho pago e no papel de mãe, levaram a construção de escalas que pudessem medi-los. Considerando a falta de medidas adequadas para avaliar estes papéis, a presente pesquisa teve como objetivo estabelecer as propriedades psicométricas em amostras brasileiras das escalas sobre a qualidade de papéis desenvolvidas nos EUA por Baruch e Barnett em 1986. Os dados vieram a partir de uma amostra de 519 mães empregadas que responderam a itens de recompensa e preocupação para cada papel. Foram realizadas análises fatoriais dos eixos principais (PAF) para identificar fatores que pudessem ser usados em análises posteriores. Os resultados encontrados asseguram confiáveis parâmetros psicométricos para as escalas, permitindo que as mesmas sejam utilizadas para mensurar a qualidade destes papéis.
\end{abstract}

Palavras-chave: Medida da qualidade de papéis, Papel de mãe, Papel de assalariada.

\begin{abstract}
Psychometric parameters of quality roles scales performed by women: Mother and paid work The necessity of assessing the women's roles quality, such as paid worker and mother roles, led to the construction of scales that could measure them. Considering the lack of adequate measures to assess these roles, the present research aimed to investigate the psychometric properties in Brazilian samples of role quality scales developed in the USA by Baruch and Barnett (1986). The data consisted of 519 employed mothers who answered items about rewards and concerns relating to each role. A factor analysis using principal axis factoring was used to identify factors that could be used in further analyses. The results show reliable psychometric parameters in the assessment of role quality.
\end{abstract}

Key words: Role quality scales, Mother role, Paid worker role.

$\mathrm{N}$ a sociedade moderna, são muitos os papéis a serem desempenhados por seus membros participantes e, cada vez mais, novos papéis são incorporados ao conjunto desempenhado, gerando um acúmulo de atividades. Muitas são as perguntas que surgem diante deste quadro. Será prejudicial à saúde física e mental dos indivíduos estarem envolvidos em tantos papéis? Quais os impactos que esta multiplicidade poderá ocasionar?

Nas últimas décadas, tem sido crescente a participação das mulheres no mercado de trabalho mundial e no Brasil não tem sido diferente (Borges \& Guimarães, 2000). Este aumento da participação tem ocorrido junto com outras transformações da sociedade, mas não foram sufi- cientes para que as mulheres tenham igualdade dentro do mercado de trabalho. Apesar da escolaridade das mulheres ser comparativamente mais elevada do que a dos homens, as condições de trabalho e remuneração tendem a ser inferiores e, ainda, podem ser consideradas limitadas às oportunidades de inserção das mulheres em posições mais qualificadas, estando estas mais restritas a alguns setores do mercado (Montagner, 2000). Isto faz com que cada vez mais aumente o interesse por estudos referentes à nova situação, principalmente porque o fato das mulheres ingressarem no mercado de trabalho não elimina suas atividades anteriores, o que é considerado como causa de conflitos e problemas, embora a idéia con- 
firmada muitas vezes seja de ganhos para as pessoas envolvidas em vários papéis, se estes se apresentarem gratificantes (Possatti, 2000). Para estudiosos, como Thoits (1983), um número maior de papéis desempenhados é importante para dar sentido à vida de uma pessoa, pois as identidades são sustentadas através dos relacionamentos de papéis.

O interesse em avaliar as conseqüências que os papéis acarretam para o bem-estar psicológico levaram a necessidade da construção de escalas que pudessem mensurá-los. A teoria de acumulação de papéis (Marks, 1977; Sieber, 1974) considera a importância de levar-se em conta aspectos positivos e negativos para avaliar se um papel é prejudicial ou não, ou seja, para saber a qualidade de um papel desempenhado é necessário que sejam mensuradas as recompensas e preocupações que compõem este papel e, então, saber se as recompensas superam os aspectos negativos do papel. Quando isto acontece podemos considerar que o papel desempenhado apresenta uma boa qualidade.

Baruch e Barnett (1986), a partir de entrevistas com mulheres, criaram escalas para o papel de mãe e do trabalho pago, compostas por itens de recompensa e preocupação, visando a avaliação destes papéis. Na população dos Estados Unidos, foram encontrados vários fatores para cada escala. Para a escala de Recompensa do Trabalho foram encontrados seis fatores: poder de decisão, desafio, ajuda a outros, reconhecimento, suporte de supervisão e satisfação com o salário. Para a escala Preocupação da Mulher com o Trabalho foram encontrados cinco fatores: sobrecarga, supervisão pobre, falta de desenvolvimento, discriminação e exposição à perigos. Para a escala Recompensa de Mãe foram encontrados quatro fatores: afeição, desenvolvimento das crianças, envolvimento familiar e companheirismo. Para a escala Preocupação de Mãe foram encontrados três fatores: descontentamento, sobrecarga e saúde e segurança das crianças (Barnett, Marshall \& Sayer, 1992). As autoras propuseram um modelo que descrevia a relação dos construtos e utilizaram uma análise fatorial confirmatória, através do Lisrel VI (para maiores detalhes ver Barnett, Marshall \& Sayer, 1992). Porém, na confirmação deste modelo muitos itens foram descartados. Teve-se, portanto, como objetivo deste trabalho, o estabelecimento de parâmetros psicométricos para tais escalas junto a população brasileira, possibilitando posteriores estudos dos possíveis impactos destes papéis no bem-estar psicológico das mulheres.

\section{Método}

\section{Amostra}

A amostra foi composta por 519 mulheres com nível de escolaridade a partir do nível médio, que desempenha- vam uma atividade remunerada e com filhos, das quais $74,8 \%$ pertenciam ao Estado da Paraíba e 25,2 \% a outros Estados do Brasil (Pernambuco, Alagoas, Maranhão, Rio Grande do Norte, Espírito Santo e Rio Grande do Sul). Com referência às profissões/ocupações desempenhadas pelas participantes da pesquisa, constaram profissionais de diversas áreas, exercendo funções de complexidade variadas, nos setores público e privado. Como exemplo podemos citar professoras, engenheiras, administradoras, médicas, enfermeiras e recepcionistas.

O nível de escolaridade mínima estipulada (ensino médio) deve-se à complexidade do instrumento aplicado e por ser este auto-administrado. Participaram mulheres com faixa etária de 21 a 60 anos, com uma média de idade de 37,4 anos $(\mathrm{DP}=7,9)$.

\section{Instrumento}

Foram utilizadas as Escalas de Qualidade de Papéis de autoria de Baruch e Barnett (1986), adaptadas (ver Apêndice) segundo as diretrizes da International Test Comission -ITC (2001). A versão para o português efetuada por um tradutor bilíngue e retraduzida ao inglês e endereçada a três juízes para que avaliassem a adequação para nossa cultura e linguagem, assegurando o entendimento das mesmas na nossa população. As escalas foram delineadas para cobrir aspectos positivos e negativos do papel da mulher no trabalho pago e no papel de mãe. A primeira escala (Qualidade do Papel do Trabalho) foi constituída de 25 itens de recompensa e 25 , de preocupação do papel do trabalho pago. A segunda escala (Qualidade do Papel dos Pais) foi constituída de 18 itens de recompensa e 20, de preocupação do papel de mãe. Para cada papel, as respondentes foram solicitadas a pensar sobre sua situação no momento atual e a indicar numa escala de 4 pontos, variando de 1 ("Não no todo") a 4 ("Extremamente"), o grau que cada um dos itens é recompensador ou preocupante.

\section{Procedimentos}

Os sujeitos foram contatados através de escolas, empresas e universidades e, por conseqüência, os questionários foram entregues pessoalmente e por terceiros. No momento da entrega, marcava-se um dia para o recolhimento e, antes do dia marcado, era feito um contato telefônico para assegurar a devolução. Este procedimento tem a desvantagem de que possa ter ocorrido a introdução de uma variável indesejável nos dados, tendo em vista a não-independência das respostas, no caso de ter ocorrido comentários sobre as questões por parte da família e de amigos. Porém, devido a impossibilidade de responderem prontamente, no local de trabalho, adotamos este procedimento na suposição de 
que este tipo de situação não seja sistemática, sendo mais para atenuar as relações que foram obtidas do que introduzir falsas relações.

Do total de questionários, 115 foram enviados através de postagem com retorno, encaminhados para outros Estados direcionados a uma pessoa da instituição ou empresa que distribuiu e recolheu os mesmos. Observou-se uma perda de $36 \%$ pois, de 830 questionários aplicados, tivemos um retorno de 531. Destes 12 foram considerados inválidos, por apresentarem uma quantidade de respostas em branco igual ou superior a três itens por cada escala, restando para análise o total de 519 questionários. $\mathrm{O}$ índice de retorno pode ser considerado adequado, mostrando-se superior ao que a literatura apresenta neste tipo de pesquisa (para revisão, ver Giles \& Feild, 1978).

\section{Resultados}

Os dados foram analisados com o uso do Statistical Package for Social Sciences (SPSSWIN - versão 7.5). Inicialmente foram realizadas análises discriminantes dos itens das escalas, com a finalidade de observar o poder de discriminação destes entre os grupos que se consideram recompensados e não-recompensados, preocupados e não-preocupados. O poder de discriminação dos itens foi calculado, através do Teste $t$ de Student para amostras independentes, verificando assim a validade discriminativa das escalas. Computou-se o índice total de cada escala e foi adotado como critério para o corte, em torno de $28 \%$ abaixo e $28 \%$ acima da distribuição. Todos os itens das quatro escalas apresentaram poder de discriminação entre os grupos, podendo portanto fazer parte das outras análises de dados. Os coeficientes resultantes da aplicação dos testes $t$ foram significativos $(\mathrm{p}<0,0001)$.

Com o objetivo de investigar e identificar um número reduzido de fatores que pudessem explicar as relações entre as variáveis, foram feitas análises fatoriais utilizando-se o método de fatoração dos eixos principais (PAF - com rotação Oblimim), sendo testada a adequação dos dados, para atender aos pressupostos necessários a esse tipo de análise multivariada (Kline, 1997; Tabachnick \& Fidell, 1996). Resolveu-se utilizar esta estratégia visto que Baruch e Barnett (1986), para confirmarem o modelo proposto, tiveram que descartar vários itens e pretendia-se saber como estas escalas se comportariam no Brasil. As seguintes medidas de adequação da amostra de itens (Kaiser-Meyer-Olkin - KMO) foram observadas: Recompensa do trabalho $=0,92$; Preocupação do trabalho $=0,93$; Recompensa de mãe $=0,94$ e Preocupação de mãe $=0,93$. Encontraram-se também os seguintes coeficientes do Teste de Esfericidade de Bartlett: para recompensa do trabalho $=4782,20$, preocupação da mulher com o trabalho $=5326,10$, recompensa de mãe $=3880,13$ e preocupação de mãe $=3989,02$ (todos com $\mathrm{p}<0,001$ ).

Após realizadas as análises fatoriais, as escalas referentes ao papel do trabalho apresentaram-se compostas por dois fatores, enquanto que as escalas do papel de mãe se apresentaram com um único fator. $\mathrm{Na}$ escala de recompensa do trabalho para as mulheres, sete itens tiveram cargas fatoriais baixas $(\leq 30)$, sendo estes retirados e permanecendo 18 itens (ver Tabela 1). O primeiro fator ficou composto por 13 itens $(24,23,16,14,20,17,18,25$, 09, 02, 08, 19, 11), apresentando um Eigenvalue de 6,34 e explicando $35,3 \%$ de variância única. Uma análise semântica dos itens que constituíram o primeiro fator indicou que os mesmos se referem ao poder de decisão na realização das atividades, liberdade de agir, trabalho estimulador e desafiante, combinados a itens ligados ao ajuste do trabalho às necessidades e interesses do indivíduo e à possibilidade de ajudar aos outros. Representa, assim, a importância da liberdade de criação e poder de execução como recompensadores no papel do trabalho, possibilitando um trabalho desafiador, no qual o indivíduo têm autonomia na realização de atividades, proporcionando controle pessoal e, por isso, com grande capacidade motivacional. Denominou-se tal Fator de Poder de Decisão.

O segundo fator ficou composto por 5 itens $(12,07,15$, 21, 06), com um Eigenvalue igual a 1,13 e explicando 6,3\% de variância única. A análise semântica dos itens indicou que estão ligados à afeição, ao respeito, ao encorajamento da supervisão imediata, à preocupação da supervisão com seus subordinados somados ao reconhecimento, ou seja, inclui itens que retratam a habilidade do supervisor em lidar com sua equipe, atuando como fonte de recompensa para seus subordinados. Traduz assim o relacionamento supervisor/subordinado, o suporte dado pelo supervisor imediato no trabalho como elemento recompensador, sendo por isso chamado Suporte de Supervisão.

A escala de itens de preocupação da mulher com o trabalho, da qual foram retirados três itens identificados com cargas fatoriais baixas $(\leq 30)$, constituiu-se finalmente por 22 itens (ver Tabela 2). Após aplicada a análise fatorial, apresentou também dois fatores. $\mathrm{O}$ primeiro $\mathrm{Fa}-$ tor ficou composto por 16 itens $(03,05,01,04,02,13,20$, 12, 07, 25, 22, 19, 24, 18, 16, 09), com um Eigenvalue de 8,05 e explicando $36,6 \%$ de variância única. A análise semântica dos itens demonstrou que eles compreendiam aspectos de falta de oportunidade para o crescimento profissional, de falta de uma supervisão adequada, de discriminação, de tarefas conflitantes, de trabalho monótono, rotineiro, de insegurança e de falta de estabilidade. 
Tabela 1. Estrutura fatorial da Escala Recompensa do Trabalho para as Mulheres

\begin{tabular}{|c|c|c|c|}
\hline Itens & Fator I & Fator II & $h^{2}$ \\
\hline Número de itens & 13 & 5 & \\
\hline 24. Ajudar outras pessoas & 0,81 & & 0,47 \\
\hline 23. A oportunidade de aprender novas coisas & 0,77 & & 0,53 \\
\hline $\begin{array}{l}\text { 16. O senso de realização e competência que você consegue por fazer o seu } \\
\text { trabalho }\end{array}$ & 0,65 & & 0,47 \\
\hline 14. Ser capaz de tomar decisões por si própria & 0,61 & & 0,36 \\
\hline 20. A liberdade para decidir como você faz seu trabalho & 0,61 & & 0,50 \\
\hline $\begin{array}{l}\text { 17. Ter a autoridade que você precisa para conseguir seu trabalho feito para } \\
\text { sua satisfação sem ter que ir para alguém mais para pedir permissão }\end{array}$ & 0,60 & & 0,39 \\
\hline 18. O seu trabalho se encaixa com seus interesses e habilidades & 0,55 & & 0,35 \\
\hline 25. Ter um impacto no que acontece no seu local de trabalho & 0,45 & & 0,27 \\
\hline $\begin{array}{l}\text { 09. Ter os recursos que você precisa para conseguir o trabalho feito } \\
\text { para a satisfação }\end{array}$ & 0,44 & & 0,29 \\
\hline 02. Trabalho desafiador ou estimulante & 0,43 & & 0,25 \\
\hline 08. Ser necessitado por outros & 0,42 & & 0,24 \\
\hline 19. O agradecimento que você consegue & 0,40 & & 0,46 \\
\hline 11. Ter horas que encaixem suas necessidades & 0,40 & & 0,25 \\
\hline 12. Afeição de seu supervisor imediato & & 0,79 & 0,61 \\
\hline 07. O respeito de seu supervisor imediato por suas habilidades & & 0,75 & 0,58 \\
\hline $\begin{array}{l}\text { 15. A preocupação do seu supervisor imediato sobre o bem-estar de } \\
\text { seus subordinados. }\end{array}$ & & 0,66 & 0,45 \\
\hline $\begin{array}{l}\text { 21. O encorajamento de seu supervisor do seu desenvolvimento } \\
\text { profissional }\end{array}$ & & 0,65 & 0,61 \\
\hline 06. O reconhecimento que você consegue & & 0,44 & 0,38 \\
\hline$\alpha$ de Cronbach & 0,87 & 0,83 & \\
\hline \% Variância & 35,3 & 6,3 & \\
\hline Eigenvalues & 6,347 & 1,135 & \\
\hline
\end{tabular}

Este fator representa o trabalho rotineiro, sem possibilidade de desenvolvimento e reconhecimento profissional, ou seja, as condições inadequadas causadas pelas difíceis relações entre supervisão, subordinados e colegas de trabalho dificultando a realização das atividades, sendo denominado Condições de Trabalho Inadequadas.

O segundo Fator ficou composto por 6 itens $(11,17$, 21, 23, 06, 08), apresentando um Eigenvalue de 1,11 e explicando 5,1\% de variância única. Uma análise semântica revelou que os itens se referiam ao desgaste físico e emocional, causado pelas atividades excessivas que nem sempre fazem parte da função e pelos conflitos decorrentes, gerando prejuízos para o bem-estar do indivíduo, criando um ambiente inóspito, inseguro e tenso e consumindo, conseqüentemente, mais energia dos indivíduos. $\mathrm{O}$ segundo fator representa assim o que se denomina Sobrecarga no Trabalho.

As escalas do papel de mãe (recompensa e preocupação) se apresentaram unifatoriais. $\mathrm{Na}$ escala de recompensa de mãe, dois itens não se adequaram por apresentarem baixas cargas fatoriais $(\leq 0,30)$, permanecendo as$\operatorname{sim} 16$ itens $(10,17,13,18,12,09,11,16,04,02,14,15,06$, 07, 03, 05). Este fator inclui itens que dizem respeito à recompensa pelo crescimento e pela realização dos fi- lhos, assim como itens que demonstram a importância de compartilhar a vida com eles, ou seja, ter um relacionamento agradável (ver Tabela 3). Este fator representa assim o elemento recompensador que atua quando existe um relacionamento de qualidade entre mães e filhos, sendo denominado de Desenvolvimento e Companhia dos Filhos.

No que se refere à escala de preocupação de mãe, foram descartados quatro itens por não se adequarem tendo apresentado cargas fatoriais baixas $(\leq 0,30)$. Esta escala ficou composta de 16 itens $(18,19,16,07,20,03,02$, $13,14,04,17,15,09,05,12,08)$ referentes à preocupação ligada ao não-atendimento de expectativas que os pais têm em relação aos filhos, aos conflitos, à diminuição do tempo para si mesmo, às responsabilidades, à saúde, à segurança, à educação e à formação (ver Tabela 4). Representa deste modo, todas as responsabilidades e as preocupações que as mães lidam no desempenho do papel de mãe, sendo por isso chamado Sobrecarga e Segurança.

\section{Discussão e Conclusão}

As escalas de Qualidade de Papéis de Mãe e do Trabalho Pago, apresentaram parâmetros psicométricos (va- 
lidade discriminante, validade fatorial e índices de consistência interna) bastante satisfatórios. Os percentuais de variância explicada demonstraram que as escalas representam adequadamente os construtos, a saber: Recompensa do trabalho com dois fatores, explicando 41 , 6\%; Preocupação da mulher com o trabalho apresentando dois fatores, explicando 41,7\%; Recompensa de Mãe, com um fator, explicando 39\%; e finalmente Preocupação de Mãe também com um fator, explicando 39,4\% da variância de construto. Todas as escalas apresentaram índices de consistência interna acima de $\alpha=0,80$, indicando com isso serem bastante confiáveis.

$\mathrm{O}$ menor número de fatores encontrados do que na escala original, leva a necessidade de algumas considerações a respeito desta diferença. Deve-se observar que as diferenças sócio-culturais não podem ser esquecidas e certamente podem ter influenciado na composição dos fatores, visto que a forma como estes papéis são construídos e vivenciados nas sociedades têm suas pe- culiaridades. Assim, algumas hipóteses merecem ser levantadas.

O primeiro ponto a ser observado é que alguns itens da escala original foram descartados neste estudo por não apresentarem carga fatorial satisfatória $(>0,30)$ : sete itens na escala de recompensa do trabalho, três na de preocupação da mulher com o trabalho, dois e quatro na escala de recompensa e preocupação de mãe respectivamente. Estes itens demonstraram não pertencerem a quaisquer dos fatores, o que certamente modificou a composição fatorial. Itens como renda e riscos para a saúde não se agruparam a nenhum fator, tanto na escala de recompensa como na de preocupação, o que deve ser observado em próximos estudos, já que os sujeitos pesquisados pertenciam a faixas salariais diferentes assim como a diferentes funções.

A desejabilidade social tem sido uma das preocupações na mensuração de alguns construtos, como por exemplo, a mensuração de aspectos da personalidade

Tabela 2. Estrutura fatorial da Escala de Preocupação da Mulher com o Trabalho

\begin{tabular}{|c|c|c|c|}
\hline Itens & Fator I & Fator II & $h^{2}$ \\
\hline Número de itens & 16 & 6 & \\
\hline 03. O trabalho não usar suas habilidades & 0,78 & & 0,50 \\
\hline $\begin{array}{l}\text { 05. A falta de respeito no seu local de trabalho por pessoas que fazem o seu } \\
\text { tipo de trabalho }\end{array}$ & 0,77 & & 0,61 \\
\hline 01. O trabalho enfadonho, monotonia, falta de variedade & 0,71 & & 0,43 \\
\hline 04. Falta de competência de seu superior imediato & 0,70 & & 0,48 \\
\hline 02. Ter pequena chance para o crescimento que você quer ou merece & 0,69 & & 0,40 \\
\hline $\begin{array}{l}\text { 13. Encarar discriminação ou assédio por causa de sua raça ou grupo } \\
\text { étnico }\end{array}$ & 0,65 & & 0,49 \\
\hline 20. Ter de fazer coisas contra suas convicções (consciência) & 0,62 & & 0,53 \\
\hline 12. A falta de gratidão de seu supervisor pelo seu trabalho & 0,61 & & 0,47 \\
\hline 07. Ser exposta a doenças ou correr risco de se machucar & 0,60 & & 0,46 \\
\hline $\begin{array}{l}\text { 25. Falta de suporte de seu supervisor para o que você precisa para } \\
\text { fazer seu trabalho }\end{array}$ & 0,57 & & 0,45 \\
\hline $\begin{array}{l}\text { 22. Oportunidades limitadas para o desenvolvimento profissional ou } \\
\text { carreira }\end{array}$ & 0,56 & & 0,33 \\
\hline 19. Encarar discriminação ou assédio por ser mulher & 0,53 & & 0,37 \\
\hline 24. Ser dependente de outra pessoa para realizar o seu trabalho & 0,50 & & 0,38 \\
\hline 18. Seu supervisor tem expectativas irreais para seu trabalho & 0,50 & & 0,35 \\
\hline 16. A possibilidade de desemprego & 0,47 & & 0,30 \\
\hline 09. Ter que manipular tarefas ou obrigações conflitantes & 0,42 & & 0,41 \\
\hline 11. Ter muita coisa para fazer & & 0,58 & 0,35 \\
\hline 17. O trabalho tira muito de você & & 0,54 & 0,28 \\
\hline 21. O trabalho ser fisicamente desgastante & & 0,52 & 0,48 \\
\hline 23. Ter de tratar com situações emocionalmente difíceis & & 0,38 & 0,40 \\
\hline $\begin{array}{l}\text { 06. Ter de fazer tarefas que você não sente que deveriam fazer parte do seu } \\
\text { trabalho }\end{array}$ & & 0,37 & 0,37 \\
\hline 08. Outras pessoas serem dependentes de você & & 0,35 & 0,32 \\
\hline$\alpha$ de Cronbach & 0,92 & 0,77 & \\
\hline \% Variância & 36,6 & 5,1 & \\
\hline Eigenvalues & 8,052 & 1,116 & \\
\hline
\end{tabular}


Tabela 3. Estrutura fatorial da Escala de Recompensa de Mãe

\begin{tabular}{lll}
\hline Itens & Fator & $\mathrm{h}^{2}$ \\
\hline número de itens & 16 & \\
\hline 10. Gostar das pessoas gentis que eles são & 0,72 & 0,52 \\
17. A companhia que eles proporcionam & 0,71 & 0,50 \\
13. Ser capaz de contar com eles para ajudar & 0,69 & 0,48 \\
18. A forma como eles mudam você para melhor & 0,69 & 0,47 \\
12. Ser capaz de conversar com eles & 0,68 & 0,46 \\
09. O sentido e objetivo que eles dão a sua vida & 0,66 & 0,43 \\
11. Ser incluída em suas vidas & 0,65 & 0,43 \\
16. O senso de responsabilidade deles com a família & 0,64 & 0,42 \\
04. A ajuda que eles dão a você & 0,65 & 0,42 \\
02. O amor que eles demonstram & 0,63 & 0,40 \\
14. Ser necessitada por eles & 0,63 & 0,39 \\
15. Compartilhar seus bons momentos & 0,62 & 0,38 \\
06. Sentir-se orgulhosa de como eles estão se tornando & 0,59 & 0,34 \\
07. Suas crianças ajudando você a ver o mundo de uma nova & 0,59 & 0,34 \\
$\quad$ maneira & & \\
03. O prazer que você consegue a partir da realização deles & 0,59 & 0,34 \\
05. Ajudar suas crianças a se desenvolverem & 0,56 & 0,31 \\
\hline & & \\
\hline \% de Cronbach & 0,92 & \\
\%Variância & 39,0 & \\
Eigenvalue & 7,016 & \\
\hline
\end{tabular}

(Ellingson, Sackett \& Hough, 1999). Quanto ao papel de mãe, deve-se considerar que em uma sociedade que educa as mulheres para serem boas mães, tendo a idéia da maternidade como algo sagrado e na qual a cultura é alimentada pelo estereótipo do amor de mãe como instintivo (Soihet, 1997), a desejabilidade social pode ter influenciado nas respostas e conseqüentemente na formação dos fatores, ou seja, pode ter ocorrido uma tendência de responder de forma a ser visto favoravelmente pela sociedade.

Portanto, aspectos como estes deverão ser investigados com maior acuidade nos próximos estudos. Devido a escassez de estudos psicométricos de instrumentos que meçam estes construtos na nossa realidade, torna-se difícil fazermos algum tipo de constatação mais acurada dos resultados até aqui encontrados.

O presente estudo procurou contribuir para avaliação da qualidade de papéis de mulheres que atuam no mercado de trabalho e que desempenhem o papel de mãe dentro da nossa realidade, podendo servir como recurso em pesquisas que tenham o propósito de verificar relações entre estas variáveis e outras, como bem-estar psicológico e saúde física. Importante também seria a validação de instrumentos que procurassem mensurar o suporte social, por exemplo, qual seria a natureza do apoio de familiares para os cuidados com os filhos. Tais medidas permitiriam conhecer melhor a qualidade dos papéis desempenhados por tal estrato populacional e verificar o quanto esta variável - suporte social - pode influenciar na qualidade dos papéis aqui mensurados.

O desenvolvimento de pesquisas correlatas permitiria um maior poder de generalização dos dados aqui apresentados. Porém, considera-se que os resultados encontrados, por terem demonstrado que as escalas utilizadas têm parâmetros de medidas confiáveis, ampliam as possibilidades de realização de pesquisas posteriormente, contribuindo como um recurso para campos de estudos que estejam preocupados com os papéis desempenhados por mulheres.

\section{Agradecimentos}

A realização desta pesquisa foi possível pelo suporte fornecido pela CAPES, órgão este ao qual gostaríamos de agradecer pelo incentivo à pesquisa científica.

\section{Referências}

Borges, A., \& Guimarães, I. B. (2000). A mulher e o mercado de trabalho nos anos noventa: o caso da região metropolitana de Salvador. In M. I. B. Rocha (Org.), Trabalho e Gênero: mudanças permanências e desafios (pp.111- 138). São Paulo: Editora 34.

Baruch, G. K., \& Barnett, R. (1986). Role quality, multiple role involvement, and psychological well-being in midlife women. Journal of Personality and Social Psychology, 51(3), 578-585.

Barnett, R. C., Marshall, N. L., \& Sayer, A. (1992). Positive-spillover effects from job to home: A closer look. Women \& Health, 19(2/3), 13 41. 
Tabela 4. Estrutura fatorial da Escala de Preocupação de Mãe

\begin{tabular}{lll}
\hline Itens & Fator & $\mathrm{h}^{2}$ \\
\hline Número de itens no fator & 16 & \\
\hline 18. Eles não virem para você quando você precisa deles & 0,73 & 0,53 \\
19. Não se sentir uma parte da vida deles & 0,72 & 0,52 \\
16. Eles não fazerem sua contribuição & 0,70 & 0,50 \\
07. Você ter muitas brigas e conflitos & 0,69 & 0,47 \\
20. Não estar certa se você está fazendo a coisa certa para eles & 0,67 & 0,45 \\
03. Suas crianças não se mostrarem agradecidos & 0,66 & 0,44 \\
02. Não ter controle suficiente sobre as crianças & 0,65 & 0,43 \\
13. Os problemas que eles podem se envolver & 0,62 & 0,39 \\
14. Sentir-se criticada pelas suas crianças & 0,61 & 0,38 \\
04. A saúde das suas crianças & 0,60 & 0,36 \\
17. Os valores ou escolhas deles preocupam você & 0,57 & 0,32 \\
15. Educação ou formação das crianças & 0,56 & 0,31 \\
09. Não ter nenhum tempo para você mesma por causa das crianças & 0,56 & 0,31 \\
05. As pesadas necessidades e responsabilidades & 0,55 & 0,30 \\
12. Sentir-se restringida por causa das crianças & 0,54 & 0,30 \\
08. A segurança deles quando eles estão longe de você & 0,52 & 0,27 \\
\hline & & \\
\hline Q de Cronbach & 0,91 & \\
\% Variância & 39,4 & \\
Eigenvalue & 6,309 & \\
\hline
\end{tabular}

Ellingson, J. E., Sackett, P. R., \& Hough, L. M. (1999). Social desirability corretions in personality measurement issues of applicant comparison and construct validity. Journal of Applied Psychology, 84(2), 155-166.

Giles, W. F., \& Feild, H. S. (1978). Effects of amount, format, and location of demographic information on questionnaire return rate and response bias of sensitive and nonsensitive items. Personnel Psychology, 31, 549-559.

International Test Commission (2001). Test Use Guidelines. [Announcement posted on the World Wide Web]. Washington: Author. Retrieved March 07, 2002 from the World Wide Web: http://www.intestcom.org/ itc_projects.htm\#ITC Guidelines on Adapting Tests.

Kline, P. (1997). An easy guide to factor analysis. London: Routledge.

Marks, S. R. (1977). Multiple roles and role strain: Some notes on human energy, time and commitment. American Sociological Review, 42, 921-936.
Montagner, P. (2000). Dinâmica e perfil do mercado de trabalho: onde estão as mulheres. In M. I. B. Rocha (Org.), Trabalho e gênero: mudanças permanências e desafios (pp.161- 167). São Paulo: Editora 34.

Possatti, I. C. (2000). Multiplicidade de papéis da mulher e seus efeitos para o bem-estar psicológico. Dissertação de mestrado não-publicada, Universidade Federal da Paraíba, Paraíba.

Sieber, S. D. (1974). Toward a theory of role accumulation. American Sociological Review, 39, 567-578.

Soihet, R. (1997). Mulheres pobres e violência no Brasil urbano. In M. D. Priore \& C. Bassanezi (Orgs.), História das mulheres no Brasil (pp.279321). São Paulo: Contexto.

Tabachnick, B. G., \& Fidell, L. S. (1996). Using multivariate statistics $\left(3^{\mathrm{a}}\right.$ ed.). New York: Harper Collins.

Thoits, P. A. (1983). Multiple identities and psychological well-being: A reformulation and test of the social isolation hypothesis. American Sociological Review, 48, 174-187. 
Izabel Cristina Possatti, mestre em Psicologia Social pela Universidade Federal da Paraiba, é professor do Departamento de Psicologia da UFPB, PB.

Mardonio Rique Dias, doutor em Psicologia Social pela Universidade de Brasília, é Professor Adjunto do Departamento de Psicologia e do Programa de Pós-graduação em Psicologia Social da UFPB, PB. Coordenador da Linha de Pesquisa “Aspectos Psicossociais de Prevenção e Saúde Coletiva”. Endereço para correspondência: Rua Geraldo Costa 820, apto. 804, Manaíra, 58038-131, João Pessoa, PB. Telefone (83)247.1352. E-mail: izapossatti@yahoo.com. 
Apêndice

\section{INSTRUMENTO}

Medida de Qualidade dos Papéis(função)

Qualidade do Papel do Trabalho

Nós estamos interessados em aprender sobre as coisas boas e as coisas más (ou ruins) em diferentes partes da vida da mulher- a gratificação ou recompensa destas coisas e também os problemas e dificuldades.

Primeiro, aqui nós temos algumas coisas que foram ditas por mulheres sobre o seu trabalho. Eu vou começar com uma lista de coisas que as mulheres disseram que acham ser recompensas sobre seu trabalho. Para cada uma, eu gostaria de saber quando você pensa sobre seu próprio trabalho, quanto, isto é uma parte recompensadora de seu trabalho.

Recompensas: Quando você pensa sobre seu atual trabalho, quanto, no todo, os seguintes itens são uma parte recompensadora de seu trabalho. Nós gostaríamos que você pensasse sobre como é exatamente agora. Nós não estamos perguntando como você desejaria que fosse, mas como é atualmente.

\section{Quanto recompensador é:}

Não é recompensador

Um pouco recompensador

Muito recompensador

Extremamente recompensador

\begin{tabular}{|c|c|c|c|c|c|}
\hline 01 & Afeição das pessoas com que você trabalha.* & 4 & 3 & 2 & $\mathbf{1}$ \\
\hline $\mathbf{0 2}$ & Trabalho desafiador ou estimulante. & 4 & 3 & 2 & $\mathbf{1}$ \\
\hline $\mathbf{0 3}$ & A renda.* & 4 & 3 & 2 & $\mathbf{1}$ \\
\hline 04 & Ser capaz de trabalhar por si própria.* & 4 & 3 & 2 & 1 \\
\hline 05 & A segurança do trabalho.* & 4 & 3 & 2 & 1 \\
\hline 06 & O reconhecimento que você consegue. & 4 & 3 & 2 & 1 \\
\hline 07 & O respeito de seu supervisor imediato por suas habilidades. & 4 & 3 & 2 & 1 \\
\hline 08 & Ser necessitado por outros. & 4 & 3 & 2 & 1 \\
\hline 09 & $\begin{array}{l}\text { Ter os recursos que você precisa para conseguir o trabalho feito } \\
\text { para a satisfação. }\end{array}$ & 4 & 3 & 2 & 1 \\
\hline 10 & Ter uma variedade de tarefas.* & 4 & 3 & 2 & 1 \\
\hline 11 & Ter horas que encaixem suas necessidades. & 4 & 3 & 2 & 1 \\
\hline 12 & Afeição do seu supervisor imediato. & 4 & 3 & 2 & 1 \\
\hline 13 & $\begin{array}{l}\text { Fazer um bom dinheiro comparado as outras pessoas em seu } \\
\text { campo.* }\end{array}$ & 4 & 3 & 2 & 1 \\
\hline 14 & Ser capaz de tomar decisões por si própria. & 4 & 3 & 2 & $\mathbf{1}$ \\
\hline
\end{tabular}


Quanto recompensador é:

Não é recompensador

Um pouco recompensador

Muito recompensador

Extremamente recompensador

\begin{tabular}{|l|l|l|l|l|l|}
\hline 15 & $\begin{array}{l}\text { A preocupação do seu supervisor imediato sobre o bem-estar de } \\
\text { Seus subordinados. }\end{array}$ & 4 & 3 & 2 & 1 \\
\hline 16 & $\begin{array}{l}\text { O senso de realização e competência que você consegue por fazer o } \\
\text { seu trabalho. }\end{array}$ & 4 & 3 & 2 & 1 \\
\hline 17 & $\begin{array}{l}\text { Ter a autoridade que você precisa para conseguir seu trabalho feito } \\
\text { para sua satisfação sem ter que ir para alguém mais para pedir } \\
\text { permissão. }\end{array}$ & 4 & 3 & 2 & 1 \\
\hline 18 & O seu trabalho se encaixa com seus interesses e habilidades. & 4 & 3 & 2 & 1 \\
\hline 19 & O agradecimento que você consegue. & 4 & 3 & 2 & 1 \\
\hline 20 & A liberdade para decidir como você faz seu trabalho. & 4 & 3 & 2 & 1 \\
\hline 21 & $\begin{array}{l}\text { O encorajamento de seu supervisor do seu desenvolvimento } \\
\text { profissional. }\end{array}$ & 4 & 3 & 2 & 1 \\
\hline 22 & Ter um impacto na vida de outras pessoas.* & 4 & 3 & 2 & 1 \\
\hline 23 & A oportunidade de aprender novas coisas. & 4 & 3 & 2 & 1 \\
\hline 24 & Ajudar outras pessoas. & 4 & 3 & 2 & 1 \\
\hline 25 & Ter um impacto no que acontece no seu local de trabalho. & 4 & 3 & 2 & 1 \\
\hline
\end{tabular}

Agora eu gostaria que você voltasse sua atenção para os aspectos problemáticos no seu trabalho. Estas são afirmações de mulheres sobre suas preocupações sobre seus trabalhos.

Quando você pensa sobre seu trabalho atual, quanto, no todo, são os seguintes itens uma preocupação para você.

Nós gostaríamos que você pensasse sobre como é agora. 
Quanto de uma preocupação é:

Não é preocupante

Um Pouco preocupante

Muito preocupante

Extremamente preocupante

\begin{tabular}{|c|c|c|c|c|c|}
\hline 01 & O trabalho enfadonho, monotonia, falta de variedade. & 4 & 3 & 2 & 1 \\
\hline 02 & Ter pequena chance para o crescimento que você quer ou merece. & 4 & 3 & 2 & 1 \\
\hline 03 & O trabalho não usar suas habilidades. & 4 & 3 & 2 & 1 \\
\hline 04 & Falta de competência de seu superior imediato. & 4 & 3 & 2 & 1 \\
\hline 05 & $\begin{array}{l}\text { A falta de respeito no seu local de trabalho por pessoas que fazem o seu } \\
\text { tipo de trabalho. }\end{array}$ & 4 & 3 & 2 & $\mathbf{1}$ \\
\hline 06 & $\begin{array}{l}\text { Ter de fazer tarefas que você não sente que deveriam fazer parte do } \\
\text { seu trabalho. }\end{array}$ & 4 & 3 & 2 & $\mathbf{1}$ \\
\hline 07 & Ser exposta a doenças ou correr risco de se machucar. & 4 & 3 & 2 & 1 \\
\hline 08 & Outras pessoas serem dependentes de você. & 4 & 3 & 2 & 1 \\
\hline 09 & Ter que manipular tarefas ou obrigações conflitantes. & 4 & 3 & 2 & 1 \\
\hline 10 & Estar insatisfeito com a renda.* & 4 & 3 & 2 & 1 \\
\hline 11 & Ter muita coisa para fazer. & 4 & 3 & 2 & 1 \\
\hline 12 & A falta de gratidão de seu supervisor pelo seu trabalho. & 4 & 3 & 2 & 1 \\
\hline 13 & $\begin{array}{l}\text { Encarar discriminação ou assédio por causa de sua raça ou grupo } \\
\text { étnico. }\end{array}$ & 4 & 3 & 2 & 1 \\
\hline 14 & Seu horário de trabalho.* & 4 & 3 & 2 & 1 \\
\hline 15 & As condições físicas no seu trabalho ( barulho, temperatura, etc.).* & 4 & 3 & 2 & 1 \\
\hline 16 & A possibilidade de desemprego. & 4 & 3 & 2 & 1 \\
\hline 17 & O trabalho tira muito de você. & 4 & 3 & 2 & 1 \\
\hline 18 & Seu supervisor tem expectativas irreais para seu trabalho. & 4 & 3 & 2 & 1 \\
\hline 19 & Encarar discriminação ou assédio por ser mulher. & 4 & 3 & 2 & 1 \\
\hline 20 & Ter de fazer coisas contra suas convicções ( consciência). & 4 & 3 & 2 & 1 \\
\hline 21 & O trabalho ser fisicamente desgastante. & 4 & 3 & 2 & 1 \\
\hline 22 & $\begin{array}{l}\text { Oportunidades limitadas para o desenvolvimento profissional ou } \\
\text { da carreira. }\end{array}$ & 4 & 3 & 2 & 1 \\
\hline 23 & Ter de tratar com situações emocionalmente difíceis. & 4 & 3 & 2 & 1 \\
\hline 24 & Ser dependente de outra pessoa para conseguir realizar o seu trabalho. & 4 & 3 & 2 & 1 \\
\hline 25 & $\begin{array}{l}\text { Falta de suporte do seu supervisor para o que você precisa para fazer } \\
\text { seu trabalho. }\end{array}$ & 4 & 3 & 2 & 1 \\
\hline
\end{tabular}




\section{QUALIDADE DO PAPEL DOS PAIS}

Agora, nós temos outra lista de coisas boas e coisas ruins mencionadas por mulheres. Neste momento, estas coisas é sobre ser mãe.

Quando você pensa sobre você como uma mãe, quanto, no todo, cada um dos itens seguintes são recompensadores ou não recompensadores para você.

Nós gostaríamos que você pensasse sobre como é isto agora. Nós não estamos perguntando como você gostaria que fosse, mas como isto realmente é.

\section{Quanto recompensador é:}

Não é recompensador

Um pouco recompensador

Muito recompensador

Extremamente recompensador

\begin{tabular}{|l|l|l|l|l|l|}
\hline 01 & Ver suas crianças amadurecer e se transformar (mudar).* & 4 & 3 & 2 & 1 \\
\hline 02 & O amor que eles demonstram. & 4 & 3 & 2 & 1 \\
\hline 03 & O prazer que você consegue a partir da realização deles. & 4 & 3 & 2 & 1 \\
\hline 04 & A ajuda que eles dão a você. & 4 & 3 & 2 & 1 \\
\hline 05 & Ajudar suas crianças a se desenvolverem. & 4 & 3 & 2 & 1 \\
\hline 06 & Sentir-se orgulhosa de como eles estão se tornando. & 4 & 3 & 2 & 1 \\
\hline 07 & Suas crianças ajudando você a ver o mundo de uma nova maneira. & 4 & 3 & 2 & 1 \\
\hline 08 & Ser a pessoa que melhor cuida deles, ser especial e insubstituível.* & 4 & 3 & 2 & 1 \\
\hline 09 & O sentido e objetivo que eles dão a sua vida. & 4 & 3 & 2 & 1 \\
\hline 10 & Gostar das pessoas gentis que eles são. & 4 & 3 & 2 & 1 \\
\hline 11 & Ser incluída em suas vidas. & 4 & 3 & 2 & 1 \\
\hline 12 & Ser capaz de conversar com eles. & 4 & 3 & 2 & 1 \\
\hline 13 & Ser capaz de contar com eles para ajudar. & 4 & 3 & 2 & 1 \\
\hline 14 & Ser necessitada por eles. & 4 & 3 & 2 & 1 \\
\hline 15 & Compartilhar seus bons momentos. & 4 & 3 & 2 & 1 \\
\hline 16 & O senso de responsabilidade deles com a família. & 4 & 3 & 2 & 1 \\
\hline 17 & A companhia que eles proporcionam. & 4 & 3 & 2 & 1 \\
\hline 18 & A forma como eles mudam você para melhor. & 4 & 3 & 2 & 1 \\
\hline
\end{tabular}

Estas são algumas das coisas que as mulheres disseram sobre as dificuldades de criar, educar, crianças. Quando você pensa sobre você como uma mãe, quanto, no todo, é cada um dos itens seguintes uma preocupação para você.

Nós gostaríamos que você pensasse sobre como é isto agora. 
Quanto de uma preocupação é:

Não é preocupante

Um Pouco preocupante

Muito preocupante

Extremamente preocupante

\begin{tabular}{|c|c|c|c|c|c|}
\hline 01 & O esforço financeiro.* & 4 & 3 & 2 & 1 \\
\hline 02 & Não ter controle suficiente sobre as crianças. & 4 & 3 & 2 & 1 \\
\hline $\mathbf{0 3}$ & Suas crianças não se mostrarem agradecidos. & 4 & 3 & 2 & 1 \\
\hline 04 & A saúde das suas crianças. & 4 & 3 & 2 & 1 \\
\hline 05 & As pesadas necessidades e responsabilidades. & 4 & 3 & 2 & 1 \\
\hline 06 & Eles precisarem menos de você a medida que vão crescendo.* & 4 & 3 & 2 & 1 \\
\hline 07 & Você ter muitas brigas e conflitos com eles. & 4 & 3 & 2 & 1 \\
\hline 08 & A segurança deles quando eles estão longe de você. & 4 & 3 & 2 & 1 \\
\hline 09 & Não ter nenhum tempo para você mesma por causa das crianças. & 4 & 3 & 2 & 1 \\
\hline 10 & Eles acharem que têm você (seu apoio)independente da situação.* & 4 & 3 & 2 & 1 \\
\hline 11 & $\begin{array}{l}\text { Perguntar-se se eles no futuro serão capazes de manter-se } \\
\text { financeiramente.* }\end{array}$ & 4 & 3 & 2 & 1 \\
\hline 12 & Sentir-se restringido por causa das crianças. & 4 & 3 & 2 & 1 \\
\hline 13 & Os problemas que eles podem se envolver. & 4 & 3 & 2 & 1 \\
\hline 14 & Sentir-se criticada pelas suas crianças. & 4 & 3 & 2 & 1 \\
\hline 15 & Educação ou formação das crianças. & 4 & 3 & 2 & 1 \\
\hline 16 & Eles não fazerem sua contribuição. & 4 & 3 & 2 & 1 \\
\hline 17 & Os valores ou escolhas deles preocupam você. & 4 & 3 & 2 & 1 \\
\hline 18 & Eles não virem para você quando você precisa deles. & 4 & 3 & 2 & 1 \\
\hline 19 & Não se sentir uma parte da vida deles. & 4 & 3 & 2 & 1 \\
\hline 20 & Não estar certa se você está fazendo a coisa certa para eles. & 4 & 3 & 2 & 1 \\
\hline
\end{tabular}

Por favor nos forneça alguns dados a seu respeito:

Idade:

anos Escolaridade:

Grau Profissão:

Estado Civil: ( ) Casada ( ) Solteira $\mathrm{N}^{\circ}$ de filhos: Idade dos filhos:

Renda Mensal: Religião:

( ) Praticante ( ) Não Praticante

* Itens retirados após análise fatorial 